\title{
Environmental Education and Biodiversity Concern: Beyond the Ecological Literacy
}

\author{
Carlos Hiroo Saito \\ Department of Ecology, Institute of Biological Sciences, \\ University of Brasilia, Cx. Postal 04457, CEP 70904-970, Brasilia-DF, Brazil
}

Received 2012-05-30, Revised 2013-01-07; Accepted 2013-02-07

\begin{abstract}
This is a review article on environmental education. The focus of the discussion is the relationship between environmental education and Biodiversity concern and the emergence of the concept of Biodiversity education. The position described here configures as a disagreement of the insertion of these innovative terminology, defending the maintenance of the term environmental education and its general framework, reserving to Biodiversity concern a position of one issue to be coped by environmental education. The general framework for environmental education arises from documents of the main international conferences, such as The Belgrado Charter, resulted from the international workshop on environmental education, the recommendations of the intergovernmental conference on environmental education held in Tbilisi and the treaty on environmental education for sustainable societies and global responsibility, in Rio de Janeiro. The present discussion also reject the criticism that environmental education is not enough socially relevant and interdisciplinary and it brings back those recommendation from the conference of Tbilisi which addressed goals for environmental education. These highlighted goals are relative to the encouragement of those ethical, economic and aesthetic values, the provision of a wide range of practical skills required in the devising and application of effective solutions to environmental problem, by linking educational processes to real life. Ecological literacy is considered limited if analyzed in its isolated form and it is defended that environmental education should go beyond a simple ecological literacy. Some concepts such as empowerment and some theoretical-methodological approach such as dialogical problemposing can help environmental education to correctly accomplish its goals and principles. A Brazilian experience on production of a didactic material known as Probio-EA for its Ministry of Environment is commented in means of the accomplishment to this theoretical proposition.
\end{abstract}

Keywords: Tbilisi, Ecological Literacy, Empowerment, Dialogical Problem-Posing Education, Probio

\section{INTRODUCTION}

The starting point of the present discussion is an article recently published addressing four challenges of what the authors have called Biodiversity education (Navarro-Perez and Tidball, 2012).

In their article, they argue that although biodiversity conservation has increasingly gained recognition, biodiversity itself is considered an ill-defined concept, based on what is said by Dreyfus et al. (1999); Kassas (2002a) and Weelie and Wals (2002). Besides this lack of clarity, they also state that biodiversity needs to be integrated outside the box of natural sciences.
Nevertheless, the sequence of their own text shows that the difficulties around the understanding of biodiversity concept and its framework are not due to an ill-definition. There is, in truth, a great complexity around this concept and its web of relationships: biodiversity involves richness and diversity on three different levels (ecosystem, species and genes) and these patterns are connected to cultural, social and economic issues, among others. When Navarro-Perez and Tidball (2012) say that the idea of biodiversity hotspot reduces the problem to certain localized geographical areas, they do not analyze properly that the scale hierarchies and the interactions of different scale levels (local, regional, 
continental and global) are a matter of correct environmental literacy and it is not a problem of illdefinition of the concept itself. Although this aspects, they insist that "biological diversity seems to be an abstract and confusing issue as a theme for education" (p.20) and this will be questioned in sequence here.

Independently of this definition (ill-defined or not), as the century progress, it can be observed the continuous keen interest in biodiversity conservation (Hungerford, 2010). This interest leads to the demands about how education could cooperate to improve biodiversity concern (Kassas, 2002a; Saito and Almeida, 2006). So, related to this, we have seen raising discussions about where is the place of biodiversity education in the context of increasing valuing of Environmental Education (EE). Is the former one a part of the latter one, a contemporary theme that environmental education should encompass, or is it a shift from the environmental education becoming a new specific field?

The answer of the following questions depends on a previous discussion about the nature of the environmental education, its definition, goals and criticism. According to Hungerford (2010), someones consider that environmental education is a way to create responsible citizenship to take decisions concerning environment, while others say that environmental education should just teach learners "about" the environment, with a strong proximity to the idea of an environmental literacy, or ecological literacy. From this debate emerges the critics by someones that environmental education is not enough socially relevant and interdisciplinary, which is highlighted by NavarroPerez and Tidball (2012).

About these debates Hungerford (2010) presents a broad view of the situation, informing that "all of these varied approaches, along with their advocates, resulted in a poorly defined mixture of philosophies about where EE should be headed" (p.2). But the same author presents his own conclusive opinion about the matter: "much of the criticism has been due largely to the failure of professional educators to explain their terms clearly, or for the critics to make a sincere effort to correctly understand terms" (p.3).

Taking into account this context, the objective of this article is to analyze the relationship between environmental education and biodiversity concern and present a theoretical-methodological framework to strengthen this integration and set in motion its application on present days.

\section{WHERE ENVIRONMENTAL EDUCATION SHOULD BE HEADED?}

At this point I should say that other debates such as Environmental Education (EE) versus Education for Sustainable Development (ESD) should be initially commented. For example, authors like Lude (2010) prefer the term education for sustainable development rather than environmental education to discuss the insertion of biodiversity and its related themes in educational projects. Kassas (2002a) said that the concept of sustainable development seemed to subsume environmental concerns (p.345). Sauve (2002) recognize this change, but she considers it a step backward which reduced environmental education as a tool for sustainable development. Marcinkowski (2010) comments the consequences of this debate inside UNESCO policies, representing a shift toward "EE in the context of ESD": "Following UNCED, staff within the UNESCO's International Environmental Education Program encouraged authors of documents in its Environmental Education Series to revise them by placing greater emphasis on sustainable topics.(...) In about 2000, this shift was highly visible; UNESCO's EE program was placed in a smaller division, whereas the ESD program was enlarged and given greater prominence, culminating in the declaration of the United Nations Decade of Education for Sustainable Development (The Decade of Education for Sustainable Development (DESD, 2005-2014) was declared) (p.4041). According to Bernard Combes, Information Officer of UNESCO, Secretariat for the DESD (posted on December 28th, 2009, available at http://www.earthzine.org/2009/12/28/united-nationsdecade-for-education-and-sustainable-development/) the declaration "entrusted UNESCO with a dual responsibility - as leader and global coordinator of the DESD and as a key implementer. The Decade aims to integrate the values inherent in sustainable development into all aspects of learning in order to encourage changes in behaviour conducive to a more sustainable and just society for all". For him, "Education for Sustainable Development (ESD) should be seen as a comprehensive package for quality education and learning within which key issues such as poverty reduction, sustainable livelihoods, climate change, gender equality, corporate social responsibility and protection of indigenous cultures, to name a few, are addressed in the perspective of sustainability. ESD seeks to develop the knowledge, skills, perspectives and values that will empower people of all ages to assume responsibility for creating and enjoying a sustainable future". 
But Marcinkowski (2010) summarizes that ESD seeks to address social, economic development and technological development goals as well as environmental goals, while EE remains interested in environmental goals as well as setting in which those goals are related to other sustainable development and ESD goals.

Here, I will keep on the focus on the Environmental Education (EE) and not call these practice as Education for Sustainable Development (ESD). To reinforce this decision, I can argue that The Treaty on Environmental Education for Sustainable Societies and Global Responsibility, of 1992, keeps this understanding that even in the context of the emergence of the sustainability and sustainable development concepts and their increasing valuing, environmental education is the central and more appropriate term. So, the correct term, concept and framework to be used here is Environmental Education.

Also, I defend here that Biodiversity is only an issue or label which has gained a contemporary visible status such as climatic change, so that it would not be adequate to talk about a biodiversity education as much as an education for climatic change.

After defining the global context of the present discussion, focusing on Environmental Education, I should comment about its historical tendencies.

One of the historical tendency of environmental education has been to teach and inform people about the environment, as it is pointed out by Hungerford (2010). This is based on the common thought that the lack of knowledge could be the main cause of people to neglect or harm to the environment (Saito et al., 2011b). The practices of producing imagery communication, transmitting information and giving lectures are the consequences of this perception about the role of environmental education. The high investment to improve the didactic of teachers at school, both for indoor and outdoor classes, is part of these practices, which are closer to what is called environmental literacy.

Another historical tendency of environmental education is directed to the development of affective awareness about environment protection. This has been mostly done by intensifying people's direct and personal experience with wild nature, provided by visiting ecological trails in protected areas. The basic argument is that urbanization has increased distance between people and nature and the proximity could develop emotional links and by this love feeling, people would become more responsible with nature. According to Forestell (1993) and Sheldrake (1994), knowledge without behavior leaves no discernible trace of change and so, we must provide an intuitive and practical understanding of nature which involve senses and the heart as well as the rational mind. According to Sauve (1999) this tendency "retained the characteristics of naturalistic romanticism" (p.14) and so, this last type of historical tendency of environmental education may be the responsible to generate those critics that environmental education is not enough socially relevant as pointed out by Navarro-Perez and Tidball (2012).

Between this two tendencies reflecting different priorities or focus of concern, much of this environmental educators developed their own focus and practices, weakly supported by a nebulous theoretical basis. Much of this environmental education practitioners creates their own definition for environmental education, increasing the range of poorly defined mixture of philosophies addressed by Hungerford (2010).

The main problem of this kind of debate, discussing two or more opposite views or focus for environmental education is that it creates a false dispute and polarization. In truth, there should not exist an opposition but really integrative and complementary approaches.

When they are taken alone themselves, one could be marked as knowledge-driven or emotional-driven, respectively linked to information inculcation or to a naturalistic ingenuity, in extreme criticism.

Another historical tendency of environmental education is related to the development of critical thinking, which mostly leads people to prosecute critical citizenry. According to Kassas (2002a), environmental education (and education for sustainability) "attempts to create an environmentally responsible population that contributes to sustainable development" (p. 346). To do so, we should make students to become critical thinkers, capable to "analyze information's provided by others and to evaluate its legitimacy" (Fretwell, 2009). According to this author, people should understand that correlation is different from causation and so, demonstrate the complexities of science. She completes her arguments saying that we should provide them with tools to find and evaluate evidences, creating self-reliance and critical thinking" (p.11). For her, one of dangers of an environmental education focused only on transmitting information is the dissemination of what she called "the science of fear", when the science itself is used to trigger a global panic without a solid scientific certainty. According to Sauve (1999), this contestatory tendency could be defined as "the socially critical environmental education movement" (p.14). In general, those who are closer to this tendency deals with the notion of socioenvironmental conflicts, assuming that the "invisible 
hand of market" tends to produce both social inequalities and nature harm. They consider that this socioenvironmental conflicts, their causative processes and main stakeholders involved should be clearly revealed as part of the environmental awareness (Saito et al., 2011a). The solution of this conflicts, in turn, can take different routes: one can say that the strengthening of social participation is necessary and enough; others can say that the manhood self-awareness and moral respect to each others would be the solution and a third group can argue in favour of a social empowerment combined with a scientific and technological mediation.

All these tendencies, with their particular focuses, should be seen as non-concurrent. If we remember the great international meetings about environmental education and their EE definitions, we will be able to see the richness of their concept: The Belgrado Charter, resulted from The International Workshop on Environmental Education in 1975 presented the Environmental Education goal as "to develop a world population that is aware of and concerned about, the environment and its associated problems and which has the knowledge, skills, attitudes, motivation and commitment to work individually and collectively towards solutions current problems and the prevention of new ones" (Yugoslavia, 1975). In 1977, The Intergovernmental Conference on Environmental Education held in Tbilisi states that "environmental education should provide the necessary knowledge for interpretation of the complex phenomena that shape the environment, encourage those ethical, economic and aesthetic values which, constituting the basis of selfdiscipline, will further the development of conduct compatible with the preservation and improvement of the environment; it should also provide a wide range of practical skills required in the devising and application of effective solutions to environmental problems" (recommendation n.1-6). The recommendation n.1-7 from the Conference of Tbilisi complements: "To carry out these tasks, environmental education should bring about a closer link between educational processes and real life, building its activities around the environmental problems that are faced by particular communities and focusing analysis on these by means of an interdisciplinary, comprehensive approach which will permit a proper understanding of environmental problems" (UNESCO, 1978).

So, although some authors like Navarro-Perez and Tidball (2012) detached the critics that environmental education is not enough socially relevant and interdisciplinary, I defend that there is sufficient robust and integrative conceptual framework and directives from these international conferences that could guide practitioners to a conscious, socially relevant and interdisciplinary development of environmental education. According to this conferences resolutions, environmental education deals with knowledge, values, attitudes, skills and competencies, stimulating the recognition of interconnections between educational processes and real life, aiming solving socioenvironmental problems. This means that, considering there is much effort and debates behind this conferences resolution, the practitioners of environmental education should mostly analyze more carefully the existent conceptual framework, especially from Tbilisi conference, instead of trying to propose their own definition, as criticized by Hungerford (2010). Much of national environmental education policies are derived from this conceptual framework, establishing a relative integrative convergence of goals and definitions around the world.

\subsection{Biodiversity as a Privileged Issue on Environmental Education}

I have assumed that I will not talk about Biodiversity education but only about Environmental Education. In this context, Biodiversity can be considered only an issue on environmental education, although it can be considered a privileged issue.

As an issue, the question is to determine perspectives that help environmental education to navigate the course of its steps, as proposed by Kassas (2002a):

- Understand ecology, which means to deal with ecological literacy, including understanding the impacts of human action on the biota

- Intimacy with nature, which means to develop a personal association with nature, including senses of wonder, enjoyment and the appreciation of its scientific, aesthetic and resource values

- Supportive society, which means dissemination of information about local and national interests and responsibilities to regional and international conventions to which each nation is committed

Kassas (2002a) also identified four aspects of learning in fields of environmental education to be applied on biodiversity concern: emotional aspects, scientific-ecological aspects, ethical aspects and political aspects. Nevertheless, he limited to relate the last one to making choices among controversial issues and competing demands, without connecting clearly to the 
comprehension of social interactions and socioenvironmental conflicts and the necessary analysis of economical driving forces and geopolitical influences. This means that we should clearly point out that political aspects encompass large field knowledge's from social sciences and we need to establish an interdisciplinary dialogue. This way, we will be able to carry out Tbilisi's recommendation for promoting interpretation of the complex phenomena that shape the environment and also for providing a wide range of practical skills required in the devising and application of effective solutions to environmental problems.

The same author, in another article (Kassas, 2002b), tried to address the gaps in knowledge that should be faced for actions to be effective and sustainable. Despite of these gaps (inventory of the global species diversity, biodiversity of the less conspicuous organisms, the role played by each species among biotic elements of ecosystems and the human ability to assess and forecast bio-ecological degradation), his major contribution is relative to the set of priorities indicated for conservation programmes: "(1) ecological indicators, species that signal the effects of perturbations; (2) keystone, pivotal species upon which the diversity of a large part of a community depends; (3) umbrellas, species with large area requirements; (4) flagships, popular, charismatic species; (5) vulnerables" (Kassas, 2002b).

Even though their importance, some comments are needed about these priorities, seeking to find contribution to educational activities, mainly for environmental education programmes. Although they could be seen as an educational generative theme, with possibilities to be unfold in several other themes, they are very focused on core aspects of biodiversity concepts with little interface with the whole set of perspectives proposed by himself in Kassas (2002a). The only one perspective that fits well in a broader perspective is the first one "Understand ecology". In truth, his purpose at this time was to develop ecological researches and provide an Ecological Literacy, not an Environmental Education.

Ecological Literacy is considered the ability to understand the ecological systems, their principle of organization and the possibilities to embody them in daily life, applying these understandings for creating sustainable societies (Wooltorton and Bennell, 2007). The term is considered firstly proposed by Orr (1989) and it currently requests "the need for understanding ecological relationships and basic thermodynamic laws and doing so through immersion in diverse natural environments" (Mitchell and Mueller, 2011). It meets expectations of Odum (1971) to improve people's capacity of understanding the patterns, cycles and systems of nature, with special emphasis on systems hierarchy and "the principle of functional integration involving additional properties with increasing complexity of structures" (p.6).

Another discussion about this issue can be found in Trombulak et al. (2004), which present the Recommended Guidelines for Conservation Literacy from the Education Committee of the Society for Conservation Biology. This guidelines are structured in a framework composed by five themes (goals, values, concepts, threats and actions) each of them organized according to primary and secondary principles. Although these guidelines are also focused mainly on Conservation (and so Ecological) Literacy, they are broader than those priorities proposed by Kassas (2002b) because includes some interfaces with other field of knowledge, when they propose analyzing themes as threats and actions and their related primary principles, such as ecological economics, impacts of human colonization in ancient times, contemporary human impacts, cascading effects, historical conditions of ecosystem, human use of nature, management of non-native species, political participation and education, among others. According to the authors, the framework they presented was structured in a hierarchical way, so that this "can even be used, in a scientifically correct manner and appropriate to local needs, in a mixed-level approach" (p.1180-1181). The goals they listed are: biological diversity, ecological integrity and ecological health, supported by concepts for understanding these goals, which are summarized as taxonomy hierarchy, ecological hierarchy, genetic diversity, the species concept, [wildlife] population growth in the environment, species distribution, communities and ecosystems, stochasticity and extinction.

They also claim that this framework was designed as an educational tool for a variety of audiences and that they believe that "education is most successful when it focuses on developing knowledge, skills and attitudes in a way that gives people extended direct experience" (Trombulak et al., 2004). Although the importance of a deep understanding of all these concepts that supports the listed goals, these concepts and the goals themselves are still limited to biological field.

\subsection{Thus, both Kassas (2002b) and Trombulak et al. (2004) are Focused on Ecological Literacy}

It is important to remember that ecological understanding involves probability and multiplas causes for events and these aspects of science "are, perhaps, the most difficult do grasp, because personal experience and 
common sense see the world rather differently" (p.182). Besides this, the complexity itself of ecological systems, should be understood supported by an hierarchical approach where environment could be perceived as a dynamic interactions among nested and non-nested entities, the constraints generated by one hierarchical level over the below ones and the rate-dependence or independence of the dynamical interaction of the constrained entities (Allen and Starr, 1982). According to Pickett et al. (1994), it is hoped the public could begin "to develop some patience for multiple causality and probability” (p.182). So, ecological literacy should be taken as something different of mere transmission of information and static knowledge, because of the complexity of the environmental knowledge and the risk of over simplification.

I cannot question the importance of an ecological literacy and the scientific-based knowledge support to sustainable practices. Nevertheless, this concept taken in its absolute form can bring an illusion that environmental literacy would be enough to solve the environmental degradation by human beings and the natural consequences for environmental education to foster scientific knowledge transmission to people.

Another point it is necessary to pay attention is about the connection between knowledge and attitudes. According to Pe'er et al. (2007), “individuals's environmental behaviours reflect their environmental literacy" (p.46). Here, it is necessary to argue that this is a very common misconception around affecting environmental education. There is no direct correspondence between environmental literacy and environmental friendly behaviour and attitudes. Saito et al. (2011b) present a case study demonstrating how researchers in ecology, who can be considered porting a high-level literacy in environmental issues (and are working directly by their researches to produce positive contributions to environmental protections) present attitudes that are harmful to environment, by leaving wastes produced by their researches in permanent experimental plots in an Ecological Reserve. In this study, the authors presented a possible explain to this behaviour referring that the cultural heritage of the Enlightenment of Bacon and Descartes could be ingrained as a collective unconscious. According to this association, especially to Francis Bacon, nature was to serve their research purposes, acquisition of diplomas and professional recognition (paradigm of domination and usage), alongside with the objectivity and emotional detachment from nature. Moreover, underneath the nobility speech of one's intentions in favour of the environment, which at that time was sacrificed for the sake of science, they were postponing to others the growth of a relationship based on respect and deference to nature. The intimacy and emotional bonding with the natural environment were subtracted in the research situation, in which the mechanical objectivity should prevail in the subject-object relationship.

This case study shows that environmental education is a broader framework than ecological literacy and it has to do with attitudes and values in addition to knowledge and skills.

From another perspective, the great risk on assuming this ecological literacy-oriented set of priorities (Kassas, 2002b) or the set of goals and concepts (in the case of Trombulak et al., 2004) is the fact that we can be worried on improving knowledge about species, their relationships, the multi-scaled diversity and the notion of richness and their ecological roles or environmental services, without paying enough attention to those processes that can put them in risk.

To seek understand and explain to much more people the ecosystem stability disruption, we should seek for a broad perspective of interconnections among different knowledge fields. To do this, we need to privilege the concept of socio-environmental conflict, which are relative to problem situations which put in evidence all those conflicts that are present in social sphere and promote environmental impacts, in these case, over the biodiversity (Saito et al., 2008). Doing this, we can properly recognize the social, cultural and economical driving forces interacting with ecological processes, as proposed by Saito et al. (2011a).

\subsection{Environmental Education, Empowerment and Biodiversity Concern: Beyond the Ecological Literacy}

From this last perspective, a socio-environmental conflict is much more than an issue; socio-environmental conflicts can behave as a methodological approach to environmental education.

This approach can be effective to make environmental education dealing with real life, aiming solving socio-environmental problems.

According to Diduck (1999) "resource and environmental managers do not manage natural systems, but manage human interactions with natural systems" and the logical consequence of this statement is that much of the resource and environmental management could be reduced to a management of conflict. The author believes that because of that, a critical 
environmental education should improve instrumental competence and communicative competence, requesting by this, the facilitation of socio-political empowerment.

The instrumental competence and communicative competence, in this case, come from Habermas' theory, which also includes the emancipatory knowledge interest (Habermas, 1972). In this theoretical framework, the instrumental competence is related to gaining capability to control and manipulate environment; the communicative competence refers to the practical domain of developing social interactions, by the intersubjectivity of the mutual understanding of intentions among people; and the emancipatory knowledge interest aims to increase awareness of the limits and possibilities to transform the social world. This social transformation could have different meanings according to historical and political context, the nature of socio-environmental conflicts and the stakeholders characteristics.

Berlinck and Saito (2010) presented a case study demonstrating how general systems theory, action research and empowerment concepts could be jointed to Habermas' theory to develop an environmental education with scientific literacy focused on water resources management. Paulo Freire's dialogical problem-posing educational approach was also included in this study (Freire, 1970; 2005).

Diduck (1999) argues that environmental education (critical environmental assessment education in his case) should adopt the notion of ecological literacy but also accepts that "progressive ecological change can only be achieved in a dialectical relationship with social change" and, in consequence, "education that improves our instrumental competence will, therefore, also include learning about the social justice of development" (p.90).

Summarizing, these last authors (Diduck, 1999; Berlinck and Saito, 2010) addressed that environmental education can port a critical and emancipatory potential while encouraging public involvement in natural resources and biodiversity management and conservation actions and policies. The environmental education should make people capable to better understand and influence the decisions about how to use land that directly and indirectly affect them, improving participatory management processes.

For example, water resources management was historically put in energy sector's hands and other users only have their rights recognized more recently, with the advent of the concept of multiple uses of water. Another example is the tropical forest which has been destroyed and their native dwellers point of view hardly could be heard.

To these processes of virtual exclusion from economic and political power Friedmann (1992) has called a "historical process of systematic disempowerment" (p.30).

To face this problem, this author defends an alternative development, which "involves a process of social and political empowerment whose long-term objective is to rebalance the structure of power in society by making state action more accountable, strengthening the powers of civil society in the management of its own affairs and making corporate business more socially responsible" (p.31). For Sadan (1997), the "process of empowerment means a transition from a state of powerlessness to a state of more control over one's life, fate and environment. The process is aimed at changing three dimensions of a social conditions to bring about a change in people's feelings and capacities, the life of collective that they belong to; and the professional practice that gets involved in the situation" (p.13). To acquire positive changes in these three dimensions, people should improve access to information, knowledge and skills, prosecute decision making and gain individual self-efficacy, community participation and perceive control (Nikkhah and Redzuan, 2009). All these means, ultimately, the enlargement of self-reliance and the recovery of the political community in civil society (Friedmann, 1987). This self-reliance enlargement represents a gain of skills that will enable them to cope more successfully with the problems of everyday life, in a more sustainable perspective (Fonchingong and Fonjong, 2002). Some environmental/ethnographic studies tried to elicit and explore different and mostly competing environmental knowledge's, including the development of an alternative use of geographic information system and remotely sensed imagery to both demonstrate the partiality of mapping technology and show possibilities for critical usage of the tool, resulting in a new understanding of the cultural meaning of landscapes and its dependency on the stakeholders roles in regional production and resource politics, as demonstrated by Robbins (2003). This kind of results can contribute to initiate a process of empowerment of those historically disempowered stakeholders.

We can see that if ecological literacy is important, it cannot be taken isolately. Thus, inside an environmental education framework, ecological literacy should be considered an instrumental knowledge interest that must be articulated to an emancipatory interest by people to get gains in self-reliance and effective actions to really 
make participatory those contemporary environmental policies, as presented in Santos et al. (2005) and Berlinck and Saito (2010).

The recommendation n.1-3 from the Conference of Tbilisi says that "A basic aim of environmental education is to succeed in making individuals and communities understand the complex nature of the natural and the built environments resulting from the interaction of their biological, physical, social, economic and cultural aspects and acquire the knowledge, values, attitudes and practical skills to participate in a responsible and effective way in anticipating and solving environmental problems and the management of the quality of the environment" (UNESCO, 1978). This means that the idea of promoting gains in self-reliance and effectiveness by scientific-oriented actions, in a interdisciplinary way, is in accordance of the guidelines from international conferences about environmental education and if we defend an interdisciplinary approach in environmental education practices, its theoretical framework also should be interdisciplinary oriented, with support from both biological and social sciences.

More, the Treaty on Environmental Education for Sustainable Societies and Global Responsibility, of 1992, adopted as one of Principles of Environmental Education for Equitable and Sustainable Societies that "Environmental education should empower all peoples and promote opportunities for grassroots democratic change and participation. This means that communities must regain control of their own destiny" (Principle 10). This is in accordance of the Strategies for the development of environmental education at the national level, proposed by the Report of the Commission to the Conference of Tbilisi: "(5) The central idea is to attain, by means of growing interdisciplinarity and of prior coordination of disciplines, a practical education oriented toward a solution of the problems of the environment, or at least to make pupils better equipped for their solution by teaching them to participate in decision-making" (UNESCO, 1978). Friedmann (1992) recognized as positive that Brazilian rubber tappers and native forest dwellers in the Amazon mobilized themselves against repeated, large-scale incursions of habitat by cattle ranchers and other commercial interests and he says that the creation of extractive reserves as a means of protecting their livelihood can be an example of empowerment. Nevertheless, this same empowerment is a never-ending story, to which we can add the necessity to develop their existential practice by ecological literacy and a collective agreement based on this knowledge. By this, in Chico Mendes Extractive Reserve in Xapuri,
Acre state, Brazil, according to the Management Plan, among other regulations, it was established that each family has the right to explore only two roads of rubber tree, where the extraction is performed for 50 days/year/road and only during two days per week for not to damage the trees. Also in this Plan, no one can break down the rubber tree (Hevea brasiliensis) or Brazil nut (Bertholletia excelsa), thus ensuring selfsustainability of this Extractive Reserve in Amazon (Saito, 2006).

This is the here addressed perspective for integrating Environmental education and Biodiversity concern, going beyond the mere ecological literacy: an environmental education aiming to empower people by the mediation of scientific and technological knowledge.

\section{A BRAZILIAN EXPERIENCE TO IMPROVE BIODIVERSITY CONCERN THROUGH ENVIRONMENTAL EDUCATION}

After describing how the relationship between environmental education and biodiversity concern should be understood, in theoretical basis, it is time to present how this guidelines and assumptions can be used to implement concrete educational practices. To do that, it will be presented the basic characteristics of an educational didactic material about Biodiversity Conservation produced in Brazil during 2005 and concluded in January of 2006. The development of this didactic material was a demand of the Project on the Conservation and Sustainable Use of Brazilian Biological Diversity of the Brazilian Ministry of the Environment (Probio/MMA) and it was named ProbioEnvironmental Education (Probio-EA).

The general theoretical-methodological bases of its development is outlined in Saito et al. (2008) and the didactic material, composed by two sets of portfolio, one Teacher book and a board game, is available at http://www.ecoa.unb.br/probioea/. The main demands of Probio/MMA about what this didactic material should contain were to deal with 6 priority issues (Brazilian Biomes, Brazilian Biodiversity, Ecosystems Fragmentation, Invasive Alien Species, Fauna Species Threatened with Extinction, Conservation Units of Nature) and to cover all Brazilian territory, that is, all Brazilian Biomes.

According to Saito et al. (2008), Probio-EA was an attempt to fulfil what is disposed in the Brazilian National Policy on Environmental Education (Federal Law n. 9,795 from April 27th, 1999) and its definition for environmental education, mostly based on The Intergovernmental Conference on Environmental 
Education held in Tbilisi: "processes through which the individual and the collectivity build social values, knowledge, skills, attitudes and competencies for the conservation of the environment, which is of common use, essential to a healthy quality of life and sustainability" (Article 1). Besides, it was also emphasized the accomplishment of some of the prescribed objectives to Environmental Education, such as, "to incentive individual and collective participation, permanent and responsible, in preserving the environment equilibrium, understanding the protection of environmental quality as a inseparable value from the exercise of citizenship" (Article 5, IV).

Also, this didactic material has its theoreticalmethodological foundations headed in Paulo Freire's dialogical problem-posing educational approach (Freire, 1970; 2005).

For the purpose to understand how the guidelines and assumptions about the interrelation among environmental education, biodiversity concerns and ecological literacy presented before is incorporated in Probio-EA, a selective synopsis of dilemmas faced during the production of the didactic material, initially commented in Saito (2012), is analyzed here below with new elements. This dilemma can be listed as the following: (1) how to produce an educational material focused in dialogical problem-posing educational approach that would come in schools across the country, without our presence together with the didactic material and even so be capable to produce the desired effects? (2) how to avoid making this educational material a mere tool for environmental rhetoric and ecological advocacy, in such a way that it could really have a consistent educational component? (3) how to make the didactic material become more than merely informative and work to promote an environmental education that makes people leave the contemplation of knowledge to engage themselves in a concrete action to change socioenvironmental conflicts? (4) how to promote equity among all the priority issues elected by Probio/MMA and among all biomes relative to each other, so that Brazilian people could effectively learn about the whole country and not only about the most famous part of Brazil? (5) how to promote literacy concerned to the articulation of geographical scales of analysis by means of this didactic material? (6) how to continue enhancing the role of the teacher as a pedagogical mediator, keeping the centrality of his office, even in the presence of this didactic material prepared in great detail to have students scientifically and technologically literated?

\subsection{Let us Examine more Carefully Each of these Dilemmas}

The first dilemma (how to produce an educational material focused in dialogical problem-posing educational approach that would come in schools across the country, without our presence together with the didactic material and even so be capable to produce the desired effects?) was solved by defending that the dialogical-problem posing approach could be implemented using the structure of two sets of portfolio, in which one set of portfolio would contain socioenvironmental conflicts (the problem) and the other one would contain the respective positive action (the solution to socio-environmental conflict). Thus, each portfolio about socio-environmental conflict or about positive action was identified and recognized by the letter " $C$ " of "Conflict" or "A" of "Action" at the top of the portfolios. Once each portfolio has a image (photograph) in the front face and a text describing the situation in the back face, the instruction was given to encourage this permanent movement from text to image and image to text. The portfolios structure has an educational strategy of encoding socio-environmental conflicts to trigger the decoding process. The decoding process ports the dialogical-problem posing approach (Freire, 1970; 2005), in which students and teacher would identify, analyze and understand the origin and mechanism of the socio-environmental conflict and the scientific and technological knowledge necessary for its solution. It should also comment that this approach is in accordance with the recommendation n.2-3 from the Conference of Tbilisi that indicates, among others, that environmental education should "emphasize the complexity of environmental problems and thus, the need to develop critical thinking and problem-solving skills" (UNESCO, 1978).

Probio-EA also differs from the major trend in Environmental Education to produce materials that depict fictional or hypothetical situations as an illustration of daily situations or problems. These current trend generates a typical kind of illustration in these materials, based on caricatured freehand drawings. The option for the description of facts, led to the identification of the actors involved, with their nominations, precise information about dates and all facts should clearly located geographically, in time and space. This also established the necessity of presenting physical evidence of the facts, which then were all illustrated by photographs rather than freehand drawings. It can be said that the presentation of real facts illustrated 
by photographs of real moments of these facts facilitates the accomplishment of the recommendation n.1-7 from the Conference of Tbilisi about the establishment of a closer link between educational processes and real life, by the recognition of the described situations by the local students.

Another aspect of the origin of this paired structure socio-environmental conflict/positive action is related to the necessity to cope with 6 priority issues (Brazilian Biomes, Brazilian Biodiversity, Ecosystems Fragmentation, Invasive Alien Species, Fauna Species Threatened with Extinction, Conservation Units of Nature) in two sets of portfolios: the first possibility examined was to distribute the 6 priority issues equally to the both set of portfolios, 3 issues for each portfolio. But this would be against one of the most established principle of environmental education that is to avoid fragmenting the knowledge. So, we decided to cope with all 6 priority issues in the same set of portfolio and we did the same with the other one, which lead us to the necessity of differentiate the two set of portfolios by their focus, not for the issue distribution. This is one more reason for the adoption of these paired structure socio-environmental conflict/positive action.

The second dilemma (how to avoid making this educational material a mere tool for environmental rhetoric and ecological advocacy, in such a way that it could really have a consistent educational component?) was solved by facing the question that if we particularize the socio-environmental conflict at local level, this could cause a disinterest and detachment from other distant school communities from the described situation and its corresponding issue. When producing the materials, we assumed that understanding the dynamics, magnitude and impact of each socio-environmental conflicts, would address to the recognition of "regularities". The regularities represent repetitive understandable pattern present both in anthropic actions (social and economical motivations and dynamics) which leads to the rupture on the equilibrium dynamic of ecosystems and living beings communities and in the resilience processes. The understanding of these regularities represents the contribution of the scientific and technological knowledge, which could be represented by ecological literacy, as much as other empowerment skills and knowledge from social sciences too. From this notion of regularity, it comes possible that every school community can transport the comprehension of the socio-environmental conflicts (problem situations) portrayed in the portfolio to new situations - their own situation or to the neighbor community situation - which experiences the same kind of socio-environmental conflicts. This is because the mining impact relative to soil loss or the effects of eutrophication on river ecosystems follows the same nature laws and properties.

One concrete example of the possibility to apply the information about one locality to others can be seen in the portfolio about Invasive Alien Species x Atlantic Forest biome: the case of the Giant African land snail (Achatina fulica). Several municipalities all over the country have been made campaigns aiming to promote the eradication of this species. Participatory processes are developed but in a wrong way and the Probio-EA made some alerts: "It is not recommended to handle these animals without guidance and monitoring of sanitary technicians, veterinarians and biologists, as the snails can transmit diseases to humans. Measures such as the use of salt, fire or chemical products, are also contraindicated, because they may cause burnings or environmental contamination. If at any location it is supposed to find the presence of large numbers of snails, the municipal authorities should be informed to make the correct identification. If, in fact, it is confirmed to be the Giant African Snail, the sanitary or municipal council is ought to take action to combat and control the problem. The community can participate in these actions, provided that they are coordinated and implemented under the guidance of experts". The central problem of the municipalities campaign is to dissimulate the government absence of responsibility by arguing in favor of social participation. This can be seen as an adaptive strategy of neoliberal policies to diminish the presence of the State and a proper debate should be held.

The possibility to make people improve participatory process with safety and self-reliance represents the correct practice of empowerment, as we have seen before with authors such as Friedmann (1987; 1992); Sadan (1997); Diduck (1999) and Nikkhah and Redzuan (2009) and we will contribute to make people more capable to evaluate the legitimacy of some false participatory campaigns promoted by local governments, in accordance of Fretwell (2009) general point of view. Once the spread of the Giant African land snail in Brazilian municipalities is a sad reality, the lessons we can get from wrong and correct campaigns can be applied in other communities. In this way, we can combat the afraid that biodiversity issue could be taken as a problem of certain localized geographical, as addressed by Navarro-Perez and Tidball (2012).

The third dilemma (how to make the didactic material become more than merely informative and work to promote an environmental education that makes 
people leave the contemplation of knowledge to engage themselves in a concrete action to change socioenvironmental conflict?) was solved combining three complementary strategies: Firstly, as already mentioned, we were headed on the concept of regularity, to make the solutions of problem situations portable to new context and localities. Secondly, based on the fact that we have explicitly given the name and the address (municipality name) of the actors involved in the positive action to solve the socio-environmental conflict described, we allowed to disclose those actions, broaden their visibility and promote the recognition of these stakeholders, whether they are a Non-Governmental Organization (NGO), the government, representative of private sector or of educational and research sector. Thirdly, we sought to give a more solid basis for the explanation of positive actions, grounded in scientific and technological knowledge, in order to enable the school community to apply the understandings about the problem situations and corresponding solutions to their own reality.

As an example, it can be presented the socioenvironmental conflict about the use of pesticides for spraying rice crops in the region of the Taim Ecological Station (near Brazilian frontier with Uruguay). The positive action described in the portfolio was the production of "ecological" whole grain rice called "Rice Friend of Taim", under the guidance and leadership of a NGO Núcleo de Educacao e Monitoramento Ambiental (NEMA). The positive action was detailed as much as possible considering the box space (number of characters) available in the design of the portfolio. That was necessarily because in a possible scenery we could have a student who was a rice farmer's son and he could get home, or attend a meeting of farmers with his father in the village, needing a consistent information support to face the adult's environmental harmful practices and explain an alternative way he learned at school. This student should be scientifically and technologically stronger in his arguments, to entail a dialogical action without being accused of practicing ecological advocacy without knowledge and life experience ground. So, after many twists and turns, we arrive at a text in the portfolio of positive action that says "The rice (Oryza sativa) is produced without pesticides in a rotating system of flooded planting plots". This part of the text leads teacher to talk about the importance of dividing the land in several plots and manage them by a rotating system to diminish pressure over the soil. The sequence of the text in the portfolio says "After the first harvest, each plot receives Azolla sp., an aquatic native plant for nitrogen fixation". This part demands that teacher explores science contents relative to biogeochemical cycles and the role of certain plant species in nitrogen fixation and the importance of this chemical element to the living beings. Following the sequence of the text in portfolio, we find that "They also used mallard (Anas boschas), which feed on seeds of competing plants and insects". This part has connection with the discussion about biological control and the role of competition and herbivory. Finally, the portfolio presents the following information: "After the second crop is planted pasture for nitrogen fixation and cattle and sheep. The association of these animals with Azolla sp. in the offseason, contributes to the fertilization of the soil. The land is prepared to receive the third planting or to rest for three or four years, promoting conservation of Wetlands". Teacher can then talk about fertilization of the soil, the use of manure and eutrophication. Once Probio-EA is a didactic material produced to basic education schools, these attention to linkage between the facts described in the portfolios and the classroom contents is permanent.

Another example of these competent linkage come from a surprisingly experience with kindergarten in a elementary school of a small city in the southern part of Brazil, when the Probio-EA was used in early childhood education (Henn, 2008). One of the issues that were analyzed at school was the socio-environmental conflict generated by the population explosion of Monk Parakeets (Myiopsitta monachus). The didactic material explained the association between the population explosion in rural areas of Rio Grande do Sul state and both the expansion of eucalyptus forestry and the expansion of maize fields. These two factors have jointly given the bird the opportunity to build protected nests in artificial forests and a food surplus. The positive action described in Probio-EA was the substitution of harmful practices such as the usage of guns for shooting the monk parakeets or the placement of poisoned baits. A new creative and sustainable practice was in progress in Piratini municipality where a mobile made by plastic, resembling a Crested Caracara (Caracara plancus) with open wings coming from the sky. The kindergarten students produced several conceptual maps with drawings of Crested Caracara connected by colored button to drawings of Monk Parakeets, or drawings of Monk Parakeets connected by dashed line to drawings of eucalyptus forestry, or other drawings of Monk Parakeets connected by colored paper balls to images of maize crops taken from magazines. Puppet show was also produced with Crested Caracara attacking Monk Parakeets. The teacher could develop environmental 
practices improving biodiversity concern of her students, simultaneously accomplishing the kindergarten educational objectives, including develop communication skills with art-education.

The fourth dilemma (how to promote equity among all the priority issues elected by Probio/MMA and among all biomes relative to each other, so that Brazilian people could effectively learn about the whole country and not only about the most famous part of Brazil?) was solved by the definition of a strategy of the development of the portfolios: We start with the idea that there was a real possibility, though not intentionally, that we ourselves could fall into the same habit and reproduce the hegemony of attention in the two mostly commented biomes (Amazon and Atlantic Forest) and thus forgot or give less attention to the other ones. To avoid this risk, we chose to build a matrix with 6 rows, each representing an issue prioritized by Probio/MMA (Brazilian biodiversity, biomes, species of Brazilian fauna threatened with extinction, fragmentation of ecosystems, invasive alien species, Conservation Units of Nature) and 7 columns, each representing a biome (Amazon, Caatinga, Cerrado, Atlantic Forest, Pantanal, Southern Fields/Pampas and Coastal and Marine Environments, the latter considered by us a biome for teaching purposes). The problem situations (or socioenvironmental conflicts) as well as their respective solution (positive actions) were referred to the intersection of row $\times$ column, constituting the joint priority issuex biome. By this way, we guarantee that at least one problem situation of each priority issues and biome was cited and analyzed in the didactic material.

Because it is a matrix structure in which the portfolios are the product of the intersection, each portfolio is identified by a heading containing the name of the priority issue and the name of the biome. This matrix structure priority issue $\mathrm{x}$ biome also generated the number of 42 portfolios so that it can be said that each priority issue (theme) is remembered by at least 7 times (at each intersection with each of the biomes) and each biome is reviewed at least 6 times (each intersection with each of these priority issues) when only a problem situation is put in the portfolio. Each biome received a different color for visual identification of the portfolio. We should still remember that, in most cases, two or three different problem situation are discussed in each sheet of portfolio further expanding the knowledge of the priority issues and biomes. For this cases, each of problem situations is numbered to correctly connect the photograph to its respective text. To complete the number of 45 sheet of portfolios, we proposed three additional portfolios with Special Topics (Caverns, Wetlands and Coral Reefs), for its uniqueness and fragility. The number 45 was chosen because this is the current number of students in the classrooms of Brazilian schools, so that each student could handle one pair of socio-environmental conflict/positive action portfolios.

This effort allows the school community in any part of the country to be in contact with the Brazilian diversity at whole, with its all variety of problem situations, biomes, ecosystems and culture. This knowledge is important because a country of continental dimensions like Brazil can be difficult to be understood in its richness and complexity and the mutual understanding is the basis for a cooperative relationship between the regions. Also, this matrix strategy can be applied in other large countries which has great internal diversity, such as the United States of America or China and it can be said that, thinking through a hierarchical viewpoint, it is possible to apply this same matrix structure to a low scale level, such as river basin, where biomes can be substituted for ecosystems if there were no internal variance in terms of biome.

So, working with this plannified matrix structure seeking for equality among geographical regions (biomes), crossed with priority issues, we can contribute to the promotion of "the encouragement of cooperation between the various regions of the country, at micro and macro-regional levels, with a view to seek for an environmentally balanced society, founded on the principles of liberty, equality, solidarity, democracy, social justice, responsibility and sustainability", as recommended by the Article $5-\mathrm{V}$ of the Brazilian National Policy on Environmental Education.

The fifth dilemma (how to promote literacy concerned to the articulation of geographical scales of analysis by means of this didactic material?) was solved by the definition of an orientation to teachers about the way to use the set of portfolios with the students in classroom. This orientation was included in the Teacher book as a sequence of four strategies, each of one representing a different scale of analysis (Saito, 2006).

Teachers are firstly oriented to give a pair of portfolio (socio-environmental conflict and respective positive action), randomly, to each student and instruct them to analyze photos and text to understand the local problem and its solution. Here, the geographical scale is local. After that, teachers are oriented to group their students to work with the portfolios of the same biome (this means that they will have in their hands the portfolios of several priority issues belonging to that biome). The aim is thus to establish connections 
(interdependencies) among the 6 priority issues of Probio/MMA within the biome. The question that could be answered is whether a socio-environmental conflict (presented as linked to one particular priority issue in that biome) can transcend that priority issue and establish visible connection to another priority issue, revealing a wider extent of the impact. In this stage of the activity, students will be building a vision of a regional scale, out of sight of local scale. A conceptual map is suggested to be made as a graphic information of the connectivities they have found. Then, students still organized in groups should receive the portfolios of the same priority issue (this time, it means that they will have in their hands those portfolios of various biomes belonging to the same priority issue). The question that could be answered now is whether a socio-environmental conflict (presented as linked to one particular biome relative to that priority issue) has the same origin or pattern of causality of other conflicts in different biomes. If a patter or regularity is recognized, there will be a basis for establishing a socio-environmental policy and action programme by government to avoid, combat and solve these socio-environmental conflicts. At this stage, students will be building a vision of national or continental scale, leaving the vision of a regional scale. The fourth activity suggests that students assemble a panel on the wall, putting up the portfolios of socioenvironmental conflict with duct tape, in such a way that the lines could represent the priority issues of Probio/MMA and the columns could represent the biomes. Thus, the students will be reconstructing the matrix structure (priority issue $\mathrm{x}$ biome) that gave rise to their own portfolios, offering everyone a beautiful panoramic view of all the portfolios and socioenvironmental conflicts portrayed. This activity enable students to move across different scale levels, which is very important to promote literacy in the articulation of geographical scales of analysis. Doing so, we will accomplish the Brazilian National Policy on Environmental Education which advocates a coordinated approach to local, regional, national and global environmental issues (Article 4-VII) and also the recommendation n.2-3 from the Conference of Tbilisi which says that environmental education should, among others, "examine major environmental issues from local, national, regional and international points of view so that students receive insights into environmental conditions in other geographical areas" (UNESCO, 1978) and we will be also attending to the identified necessity of improving understandings about system hierarchies (Odum, 1971; Allen and Starr, 1988). Besides, I can argue that this kind of activity is necessary to make people more capable to "think globally and act locally", because behind this marvelous sentences there is a conceptual and operational difficulties which refers to the ability (skill and competences) to promote coordination between geographic scales and this ability is a matter of literacy we should promote, by a wellplanned educational strategies. Finally, these exercises about migration of scale levels permit people to change the focus of analysis and to develop processes of detachment from local reality. This can lead them to a better articulation of concepts, to a wider understanding of processes and to a integrative and critical perception of macro-structural relationship among variables, which is fundamental for the exercise of the citizenship.

The sixth dilemma (how to continue enhancing the role of the teacher as a pedagogical mediator, keeping the centrality of his office, even in the presence of this didactic material prepared in great detail to have students scientifically and technologically literated?) was solved by increasing teacher's role in guiding students on the usage of Probio-EA. One of the strategies adopted was the introduction of distinction in the language of the portfolio of socio-environmental conflicts (which would be the first one to be handled by the students), relative to the portfolio of positive action. The former should have a simple everyday language, without explicit scientific terms or concepts. However, the portfolio of positive actions should present a more elaborate scientific language, so that the learner could ascend to a higher level of knowledge. But the passage from one language level to another, from one portfolio to another, should be made through the mediation of the teacher, who would develop the understanding of concepts and scientific terms in classroom. So, we did not produced this didactic material thinking it could be used alone, in spite of the teacher. On the contrary, it should be used with the teacher, guided by the teacher in classroom. Just to illustrate this, it will be presented the following two different extracts of introduction of the same portfolio about Fragmentation of Ecosystem x cerrado biome, one from the socio-environmental conflict portfolio and the other from the positive actions one. "The second major type of vegetation, the Brazilian Cerrado, is suffering increasing losses and becoming increasingly small. The natural areas of Cerrado are increasingly isolated and smaller and those who have not declined are likely to be altered, even when they are protected" (socioenvironmental conflicts portfolio); "About $80 \%$ of charcoal consumed in Brazil comes from trees of the Cerrado Biome. The second largest Brazilian type of 
vegetation has suffered mounting losses in its original cover, been submitted to the fragmentation of ecosystems. As a result, the Cerrado is today considered one of the 25 Hotspots of the world" (positive actions portfolio). This last portfolio presents concepts as Fragmentation of Ecosystems (the priority issue focused in the portfolio), biome and the concept of hotspot, which was originally presented by Myers et al. (2000) and then suffered revisions to increase the number of hotspots from the initial 25 ones. As can be seen, the expressions Fragmentation of Ecosystem and biome are not employed in the portfolio of socio-environmental conflicts portfolio, although the idea is present in a more colloquial language. However, it clearly appears in positive actions portfolio, where the terms are presented on fully extent and repeatedly, for the purpose of setting the learning. Even the scientific names of species are presented only in the positive actions portfolio, believing that the teacher has exercised its role when introducing the classification of living beings. Finally, the didactic material was produced with the intention that teacher could exploit it for a long period of classes within a pedagogical planning that allows the direct use of the terms and concepts present in portfolios with other supplementary lessons. The experience already described of Henn (2008) is illustrative of the teacher's role in educational process. To reinforce this idea, Henn (2008) also demonstrates that students, guided by their teacher, investigated the past food consumption by interviewing older people in their community and when comparing with the present food selling on the local market-place, concluded for the diversity decrease, due to the greater uniformity produced by commodities market. When kindergarten students decided to collectively write a letter to local farmers to increase diversity of foods to be sold at the local market-place, they are trying to take their future in their own hands - a manifestation of a increasing empowerment, mediated by teacher's work.

I have also to include an additional dilemma and comment about the board game that is part of ProbioEA: how to develop a cooperative game which could be keep players interest and still port a empowering and dialogical problem-posing approach? This is a cooperative board game, in which the players do not compete with each other, in opposition to currently adversarial model present in games, even educational games. The produced game has the main objective of assisting each animal to arrive at their respective natural habitat, preventing them to be extinct from the nature. A functional element in this board game is the presence of a system of payment and receipt of cash and bonds, which seeks to represent the dynamics of fines (penalties) for environmental crimes. In Brazilian national environmental policy, there is the figure of the National Environment Fund (FNMA/MMA), which receives $10 \%$ of the collected amount from these fines. Besides the opportunity to know about the existence of FNMA/MMA, the board game creates several situations in which mathematics knowledge is necessary to calculate the value corresponding to this $10 \%$ from different ways: $1 / 10 ; 0.1 ; 2 / 20$ and so on, aiming to promote some interactions between different science fields. Another important element in the dynamics of the board game is the kinship with the animals which are all members of the Brazilian Biodiversity: eight animals were selected to play; all of them are present in portfolios. Seven animals represent a different Brazilian biome and the eighth one is representative of the wetlands; six of them are included in the National List of Endangered Species of Brazilian Fauna. The degree of threat, represented by the category in which the endangered species is classified (vulnerable, endangered, critically endangered) determine the amount to be paid to save a species in the board game. This is why, in real life, those most threatened species require a higher level of investment (financial resources) in projects to achieve its conservation goals. The species that are not part of the National List of Endangered Species of Brazilian Fauna may be covered with initiatives for conservation, but will receive lower priority in terms of public policy and therefore have a lower value to be paid and to save them in the game. All players should cooperate joining their respective amount of money to save one species from extinction and sometimes during the board game the players have to take decision about which one of the set of species should be chosen to be saved in agreement. Doing so, it is possible to contribute in preparing young people to manage difficulties and learn to take decisions cooperatively.

All the Probio-EA, at least, was produced to accomplish the main goals and principles of environmental education present in Brazilian National Policy on Environmental Education, mainly when it is said to promote "the development of an integrated understanding of the environment in its multiple and complex relations, involving ecological, psychological, legal, political, social, economic, scientific, cultural and ethical aspects" (Article 5-I) and "the encouragement and strengthening of a critical awareness of environmental and social issues" (Article 5-IV). These goals and principles are also in accordance with those recommended by the Conference of Tbilisi. 


\section{CONCLUSION}

Here, at first, it was made a defense of the Environmental Education as the main framework for handling with people concern about environment, sustainability and biodiversity conservation. Then, it was made a focus on principles and goals of the Intergovernmental Conference on Environmental Education held in Tbilisi, in a way to valorize them. One of the recommendation remembered here is the recommendation n.1-7 which addressed to the importance of connect educational processes to real life, so to make people capable to face environmental problems armed by an interdisciplinary, comprehensive approach which will permit a proper understanding of these problems. The ecological literacy was recognized as important, once permits people improve access to information, knowledge and skills, but it should not considered enough once social sciences contribution by empowerment concept is also equally important to people prosecute decision making and gain individual and collective self-reliance. This complexity of the framework involving environmental education addresses the necessity to develop a careful debate about where environmental education should be headed and to where it should be going and beyond what. Especially, it is argued that it is not necessary to create new terms or adjectives to environmental education, nor new definitions: this will only widen the multiplicity of definitions, approaches and confusions. Before efforts to create names and derivations, we should read again the resolutions of the main international historical conferences on environmental education, such as The Belgrado Charter, resulted from The International Workshop on Environmental Education in 1975, the recommendations from The Intergovernmental Conference on Environmental Education held in Tbilisi in 1977 and The Treaty on Environmental Education for Sustainable Societies and Global Responsibility, of 1992. The Brazilian experience of producing a didactic material (Probio-EA) seeking for the accomplishment of these principals and goals, with a reference on dialogical problem-posing theoretical foundation, was an example of the successful possibility of this way of thinking.

\section{REFERENCES}

Allen, T.F.H. and T.B. Starr, 1988. Hierarchy: Perspectives for Ecological Complexity. 1st Edn., University of Chicago Press, Chicago, ISBN-10: 0226014320, pp: 310 .
Berlinck, C.N. and C.H. Saito, 2010. Action research for emancipation informed by habermas and hierarchy of systems: Case study on environmental education and management of water resources in Brazil. Syst. Practice Action Res., 23: 143-156. DOI: 10.1007/s11213-009-9150-z

Diduck, A., 1999. Critical education in resource and environmental management: Learning and empowerment for a sustainable future. J. Environ. Manage., $\quad 57: \quad 85-97 . \quad$ DOI: 10.1006/jema.1999.0289

Dreyfus, A., A.E.J. Wals and D.V. Weelie, 1999. Biodiversity as a Postmodern theme for environmental education. Canadian J. Environ. Educ., 4: 155-175.

Fonchingong, C.C. and L.N. Fonjong, 2002. The concept of self-reliance in community development initiatives in the Cameroon Grassfields. GeoJournal, 57: 83-94. DOI: 10.1023/A:1026042718043

Forestell, P.H., 1993. If Leviathan has a face, does Gaia have a soul?: Incorporating environmental education in marine eco-tourism programs. Ocean Coastal Manage., 20: 267-282. DOI: 10.1016/09645691(93)90070-F

Freire, P., 1970. Pedagogy of the Oppressed. 1st Edn., Herder and Herder, New York, ISBN-10: 0816491321, pp: 186.

Freire, P., 2005. Education for Critical Consciousness. 1st Edn., Continuum International Publishing Group, London, ISBN-10: 082647795X, pp: 160.

Fretwell, H., 2009. Environmental education: The science of fear. Perc. Reports, 27: 8-11.

Friedmann, J., 1987. Planning in the Public Domain: From Knowledge to Action. 1st Edn., Princeton University Press, Princeton, ISBN-10: 0691022682, pp: 501.

Friedmann, J., 1992. Empowerment: The Politics of Alternative Development. 1st Edn., John Wiley and Sons Incorporated, Cambridge, ISBN-10: 1557862990, pp: 196.

Habermas, J., 1972. Knowledge and Human Interests. 1st Edn., Beacon Press, Boston, ISBN-10: 0807015415, pp: 368.

Henn, R., 2008. Master degree Dissertation (Mestrado em Educacao). Universidade Federal de Santa Maria/Graduated course in Education, Santa MariaRS, pp: 424.

Hungerford, H.R., 2010. Environmental Education (EE) for the 21st Century: Where have we been? Where are we now? Where are we headed? J. Environ. Educ., 41: 1-6. DOI: 10.1080/00958960903206773

Kassas, M., 2002a. Environmental education: Biodiversity. Environmentalist, 22: 345-351. DOI: 10.1023/A:1020766914456 
Kassas, M., 2002b. Biodiversity: gaps in knowledge. $\begin{array}{lll}\text { Environmentalist, } & \text { 22: } & \text { 43-49. DOI: }\end{array}$ 10.1023/A:1014520024945

Lude, A., 2010. The spirit of Teaching ESD-Biodiversity in Educational Projects. In: Biodiversity in Education for Sustainable Development-Reflection on School-Research Cooperation, Ulbrich K., J. Settele and F.F. Benedict (Eds.), Pensoft, Sofia/Moscow, ISBN-13: 9789546425379, pp: 17-29.

Marcinkowski, T.J., 2010. Contemporary challenges and opportunities in environmental education: Where are we headed and what deserves our attention? J. Environ. Educ., 41: 34-54. DOI: 10.1080/00958960903210015

Mitchell, D.B. and M.P. Mueller, 2011. A philosophical analysis of David Orr's theory of ecological literacy: Biophilia, ecojustice and moral education in school learning communities. Cultural Stud. Sci. Educ., 6: 193-221. DOI: 10.1007/s11422-010-9274-6

Myers, N., R.A. Mittermeier, C.G. Mittermeier, G.A.B. da Fonseca and J. Kent, 2000. Biodiversity hotspots for conservation priorities. Nature, 403: 853-858. DOI: $10.1038 / 35002501$

Navarro-Perez, M. and K.G. Tidball, 2012. Challenges of biodiversity education: A review of education strategies for biodiversity education. Int. Elect. J. Environ. Educ., 2: 13-30.

Nikkhah, H.A. and M. Redzuan, 2009. Participation as a medium of empowerment in community development. Eur. J. Soc. Sci., 11: 170-176.

Odum, E.P., 1971. Fundamentals of Ecology. 3rd Edn., Saunders, Philadelphia, pp: 574.

Orr, D.W., 1989. Ecological literacy. Conserv. Biol., 3: 334-335. DOI: 10.1111/j.1523-1739.1989.tb00238.x

Pe'er, S., D. Goldman and B. Yavetz, 2007. Environmental literacy in teacher training: Attitudes, knowledge and environmental behavior of beginning students. J. Environ. Educ., 39: 45-59. DOI: 10.3200/JOEE.39.1.45-59

Pickett, S.T.A., J. Kolasa and C.G. Jones, 1994. Ecological Understanding. 1st Edn., Academic Press, San Diego, ISBN-10: 012554720X, pp: 206.

Robbins, P., 2003. Beyond ground truth: GIS and the environmental knowledge of herders, professional foresters and other traditional communities. Hum. Ecol., 31: 233-253. DOI: 10.1023/A:1023932829887

Sadan, E., 1997. Empowerment and community planning. Translated from Hebrew by Richard Flantz, Elisheva Sadan.

Saito, C.H. and L.E. Almeida, 2006. Conservação da Biodiversidade e a valorização do componente educacional. Floresta Ambiente, 13: 66-74.

Saito, C.H., 2006. Educacao Ambiental PROBIO: Livro do professor. 1st Edn., MMA/SBF, National Government Publication, Brasília, ISBN-10: 8587166883, pp: 124.
Saito, C.H., 2012. Os desafios contemporâneos da Política de Educação Ambiental: Dilemas e escolhas na produção do material didatico. In: Educação Ambiental: Abordagens múltiplas, Ruscheinsky, A., (Ed.), Porto Alegre, Penso, pp: 266-266.

Saito, C.H., A. Ruscheinsky, F.P. Bastos, J.B.A. Nunes and L.F. Silva et al., 2011a. Conflitos socioambientais, educação ambiental e participação social na gestão ambiental. Sustentabilidade Debate, 2: 121-138.

Saito, C.H., F.P. Bastos, I. Abegg, 2008. Teorias-guia educacionais da produção dos materiais didáticos para a transversalidade curricular do meio ambiente do MMA. Revista Iberoamericana Educ., 45: 1-10.

Saito, C.H., M.R. Gomes and L.E. Almeida, 2011b. Does a baconian vision of nature dominate among researchers in ecology? A case study in an ecological reserve of the IBGE in central Brazil. Hum. Ecol., 39: 835-839. DOI: 10.1007/s10745011-9440-9

Santos, I.A. C.N. Berlinck, S.C.S. Araujo, E.T. Steinke and V.A. Steinke et al., 2005. The centrality of the "mediation" concept in the participatory management of water resources. Canadian J. Environ. Educ., Ontario, 10: 180-194.

Sauve, L., 1999. Environmental Education between modernity and postmodernity: Searching for an integrating educational framework. Canadian J. Environ. Educ., 4: 9-35.

Sauve, L., 2002. Environmental education: Possibilities and constraints. Connect-UNESCO Int. Sci. Technol. Environ. Educ. Newsletter, 27: 1-2.

Sheldrake, R., 1994. The Rebirth of Nature: The Greening of Science and God. 1st Edn., Park Street Press, Rochester, Vermont, ISBN-10: 0892815108, pp. 272.

Trombulak, S.C., K.S. Omland, J.A. Robinson, J.J. Lusk and T.L. Fleischner et al., 2004. Principles of conservation biology: Recommended guidelines for conservation literacy from the education committee of the society forconservation biology. Conserv. Biol., 18: 1180-1190. DOI: 10.1111/j.15231739.2004.01851.x

UNESCO, 1978. Intergovernmental Conference on Environmental Education. Tbilsi (USSR), UNESCO, Paris.

Weelie, D.V. and E.J. Wals, 2002. Making biodiversity meaningful through environmental education. Int. J. Sci. Educ., 24: 1143-1153. DOI: $10.1080 / 09500690210134839$

Wooltorton, S. and D. Bennell, 2007. Ecological literacy: Noongar way. Every Child Mag. Build. Collaborative Communit., 13: 30-31.

Yugoslavia, B., 1975. The international workshop on environmental education. The International Environmental Education programme, Unesco. 